\title{
Eggs and hatchlings variations in desert locusts: phase related characteristics and starvation tolerance
}

\author{
Koutaro O. Maeno ${ }^{1,2 *}$, Cyril Piou ${ }^{1}$, Mohamed A. Ould Babah ${ }^{2}$ and Satoshi Nakamura ${ }^{3}$ \\ ${ }^{1}$ CIRAD, UMR CBGP, F-34398 Montpellier, France \\ 2 The Mauritanian Desert Locust Centre, Centre National de Lutte Antiacridienne, Nouakchott, Mauritania \\ ${ }^{3}$ Japan International Research Center for Agricultural Sciences, Tsukuba, Japan
}

Edited by:

Toru Miura, Hokkaido University,

Japan

\section{Reviewed by:}

Kathleen S. Curtis, Oklahoma State

University Center for Health

Sciences, USA

Cheng X. Qin, Baker IDI Heart and

Diabetes Institute, Australia

\section{*Correspondence:}

Koutaro O. Maeno, Centre National de Lutte Antiacridienne, Nouakchott, Bp: 665, Mauritania

e-mail: otokomaeno@yahoo.co.jp
Locusts are grasshopper species that express phase polyphenism: modifying their behavior, morphology, coloration, life history and physiology in response to crowding. Desert locusts, Schistocerca gregaria, epigenetically modify progeny quality and quantity in response to crowding. Gregarious (crowded) females produce larger but fewer progeny than do solitarious (isolated) ones. The variability of progeny quality within single egg pod and the reasons why gregarious progeny have a better survival rate than solitarious ones remains unclear. This study investigated 1) the effects of rearing density on the variation in egg size within single egg pods 2 ) the starvation tolerance of hatchlings from mothers with different phases and 3) the physiological differences in hatchling energy reserve. Isolated females produced smaller but more eggs than did crowded ones. The variation in egg size within egg pods was greater in the latter than in the former. A negative relationship between egg size and number of eggs per egg pod was observed for both groups. Under starvation conditions, gregarious hatchlings survived significantly longer than solitarious ones. Among the solitarious hatchlings, the survival time was longer with increased hatchling body size. However, small individuals survived as long as large ones among the gregarious hatchlings. The percentage of water content per fresh body weight was almost equal between the two phases, before and after starvation. In contrast, the percentage of lipid content per dry body weight was significantly higher in gregarious hatchlings than in solitarious ones before starvation, but became almost equal after starvation. These results demonstrate that female locusts not only trade-off to modify their progeny size and number, but also vary progenies' energy reserves. We hypothesize that gregarious females enhance their fitness by producing progeny differently adapted to high environmental variability and particularly to starvation conditions.

Keywords: density-dependent phase polyphenism, maternal effect, progeny size and number, locusts, Schistocerca gregaria, starvation resistance, risk-spreading strategies

\section{INTRODUCTION}

Plasticity and diversification of the characteristics of progeny produced by single individuals appear adaptive to unpredictable and unstable environments as a risk-spreading strategy (Capinera, 1979; Kaplan and Cooper, 1984; Hopper, 1999). Phase polyphenism observed in locusts is a well-known example of reproductive plasticity (Uvarov, 1966; Pener, 1991; Pener and Yerushalmi, 1998; Pener and Simpson, 2009; Verlinden et al., 2009). For example, locusts grown at a low population density (solitarious phase) are characterized by cryptic body coloration and solitary and sedentary habits, whereas those at a high population density (gregarious phase) are characterized by a conspicuous body coloration and gregarious and migratory habits. The variation in these traits is not discrete but continuous, and intermediate forms (transient phase) with intermediate characteristics are observed under certain conditions. In the desert locust, Schistocerca gregaria (Forskål), gregarious females occurring in high density populations produce fewer but larger eggs than do the solitarious females that occur in low population densities (Norris, 1952; Uvarov, 1966; Injeyan and Tobe, 1981; Pener, 1991). In the laboratory, the eggs of isolated-reared females typically produce green and small hatchling characteristic of solitarious phase, whereas those laid by crowd-reared ones mainly produce black and large hatchlings characteristic of gregarious phase (Hunter-Jones, 1958). Although the phase-related differences between solitarious and gregarious hatchlings have been frequently reported (Hunter-Jones, 1958; Uvarov, 1966; Bouaïchi et al., 1995; Simpson et al., 1999; Maeno and Tanaka, 2007, 2008a), the variation in progeny size within a single egg pod and the ecological functions of progeny body size are still poorly understood.

In S. gregaria, single egg pods laid either by solitarious or gregarious phases have been documented to occasionally contain a mixture of hatchlings with green, intermediate or black body coloration (Faure, 1932; Husain and Ahmad, 1936; Hunter-Jones, 1958; Bouaïchi et al., 1995; McCaffery et al., 1998). This indicates that single egg pods contain different egg sizes, because egg size is closely correlated with hatchling body coloration (Tanaka 
and Maeno, 2008; Maeno and Tanaka, 2008b). The female desert locusts can flexibly and rapidly modify the quality and quantity of their progeny in response to a change in the rearing density during the adult stage (Bouaïchi et al., 1995; Maeno and Tanaka, 2008a). Timing and duration of crowding experienced by the mothers during a sensitive stage of oocyte development stimulates a shift from the production of small eggs to large ones and vice versa (Maeno and Tanaka, 2010). The primary factor causing progeny gregarization was found to be the tactile stimulus perceived by the antenna (Maeno et al., 2011). Although the mechanisms controlling hatchling characteristics have been addressed from biochemical, physiological and hormonal approaches (Islam et al., 1994; Bouaïchi et al., 1995; McCaffery et al., 1998; Simpson et al., 1999; Hägele et al., 2000; Pener and Simpson, 2009; Maeno and Tanaka, 2012; Van Wielendaele et al., 2012), very scarce information is available regarding the phase-related variation of egg size within a single egg pod in S. gregaria. This information becomes essential to understand the mechanism controlling progeny quality and quantity. First, the present study investigated the variation of egg size within egg pods, derived from either isolated- or crowd-reared females, to obtain fundamental information.

Progeny body size influences their developmental and reproductive performance during their own lifetime (Fox and Czesak, 2000). In general, larger progeny exhibit better performance than do smaller sized ones. In S. gregaria, the large body size of gregarious hatchlings is likely to be adaptive to adverse conditions, because they show a higher tolerance to desiccation, fasting and poor food conditions than smaller hatchlings of solitarious phase (Albrecht and Blackith, 1960; Maeno and Tanaka, 2011). However, most of the earlier studies investigating the relationship between the phase-related characteristics of the hatchlings and fitness-related performance did not consider the individual variation in hatchling body size. Furthermore, the way in which gregarious hatchlings physiologically accomplish better survival than solitarious ones still remains unclear. Consequently, the adaptive mechanisms of maternal effects on reproduction and progeny fitness in different environments are not well understood (Pener and Simpson, 2009). Therefore, to address these problems, the present study examined the survival of solitarious and gregarious hatchlings individually under starvation conditions. Finally, we examined the physiological changes including the water and lipid contents as the initial energy reserve related to starvation in order to determine the phase-related survival strategies. Investigating the physiological mechanisms involved in producing different qualities of hatchlings from individuals with different maternal histories should help in understanding the ecological role of phase-related characteristics of hatchlings in S. gregaria.

\section{MATERIALS AND METHODS INSECTS AND REARING CONDITIONS}

The $S$. gregaria individuals studied in the present paper were the 6 th generation of a new line collected close to Akjoujt $\left(\mathrm{N} 19^{\circ} 45^{\prime}\right.$, $\left.\mathrm{W} 14^{\circ} 23^{\prime}\right)$ in Mauritania where gregarization of desert locust occur (Babah, 2010). Nymphs and adults were maintained in the Cirad's laboratory, in Montpellier, in groups of approximately 100 individuals in large cages $(40 \times 40 \times 42 \mathrm{~cm})$ or isolated in small cages $(12 \times 12 \times 10 \mathrm{~cm})$ at $31 \pm 1^{\circ} \mathrm{C}$, with a $12: 12 \mathrm{~h}$ light:dark photoperiod under $40-60 \%$ relative humidity, in a well-ventilated room. They were fed fresh wheat grass leaves as well as wheat bran.

\section{EFFECT OF REARING DENSITY ON THE EGG SIZE, NUMBER AND VARIANCE IN EGG SIZE WITHIN A SINGLE EGG POD}

In S. gregaria, rearing density during an adult stage influences the number and size of eggs (Hunter-Jones, 1958; Injeyan and Tobe, 1981; Maeno and Tanaka, 2008a). To confirm this phenomenon for our strain, female locusts reared under crowded conditions as nymphs were placed either under crowded conditions (in a large cage) or isolated in a small boxes, after adult emergence. Each isolated-reared female was paired with a sexually mature male for mating once $(<24 \mathrm{~h})$ and allowed to lay egg pods.

Plastic cups (diameter, $5 \mathrm{~cm}$; height, $10 \mathrm{~cm}$ ) filled with clean moist sand were placed in the cages to collect the egg pods. Egg pods collected during the first two months after adult emergence were incubated at $31 \pm 1^{\circ} \mathrm{C}$. Two days after egg deposition, eggs were taken one by one, beginning from the lower to the upper portion of the egg pod. These eggs were then placed on a piece of moist tissue paper to avoid desiccation before egg length measurements. Egg length is highly correlated with egg weight (Maeno and Tanaka, 2008b), so the present study measured only egg length to the nearest $0.1 \mathrm{~mm}$ using an ocular micrometer installed in a stereo microscope. The number of eggs in each egg pod was counted at that time. Next, all eggs from a single egg pod were placed on moist tissue paper in a plastic container (diameter, $10 \mathrm{~cm}$; height, $10 \mathrm{~cm}$ ) and returned to the same temperature until hatching. Hatchlings from these egg pods were used for the other experiments described below.

\section{RELATIONSHIP BETWEEN VARIATION IN EGG SIZE AND THEIR POSITION IN THE EGG POD}

To determine whether variation in egg size was dependent upon the position in the egg pod, the eggs in each egg pod were divided into three, based on their position of occurrence, i.e., upper, middle and lower regions. All intact eggs within a single egg pod were measured as described above. Curved eggs and eggs broken by handling were not measured but counted.

\section{SCORING OF HATCHLING BODY COLOR AND BODY WEIGHT}

Hatchlings were divided into five hatchling color groups (HCGs 1-5) according to Maeno and Tanaka (2007): HCG 1, green body color without dark spots; HCG 2-4, increasingly darker body color; HCG 5, almost wholly black body color. After body color was scored, the hatchlings were weighed individually to the nearest $0.1 \mathrm{mg}$ with an electronic balance (METTLER AE260). Hatching was observed twice per day (9:00 or 16:00). Due to observation time, the present study used individuals not older than $15 \mathrm{~h}$ after hatching. After recording of hatchling body color and body weight, they were used for the starvation experiments described below.

\section{MATERNAL EFFECTS ON STARVATION TOLERANCE OF HATCHLINGS}

The starvation experiment was performed using hatchlings obtained from either isolated- or crowd-reared females in the same rearing room as described above. Desert locusts produce typical solitarious and gregarious hatchlings depending on the 
rearing density during the adult stage, irrespective of the rearing density before the mother reached the adult stage (Hunter-Jones, 1958). If the rearing density of the mother and the progeny are identical (i.e., isolated or crowded), the progeny develop adult morphometrics with the typical solitarious and gregarious morphology, respectively (Maeno and Tanaka, 2009a). For simplification, in this study, hatchlings derived from isolatedand crowd-reared females will be termed solitarious and gregarious hatchlings, respectively. Solitarious and gregarious hatchlings were housed individually in a transparent plastic cylinder (diameter: $3 \mathrm{~cm}$, height: $10 \mathrm{~cm}$ ) with a piece of moist tissue paper, after being weighed on the day of hatching. Mortality was recorded twice every day. Data from the females and males were pooled.

\section{MATERNAL EFFECTS ON THE PHYSIOLOGICAL TRAITS OF HATCHLINGS ASSOCIATED WITH STARVATION}

To determine the influence of starvation on the physiological changes in the hatchlings, fresh body weight within $15 \mathrm{~h}$ after hatching, dry body weight, water content as well as lipid content were examined. Two groups were used to measure the total water and lipid contents as physiological characteristics for solitarious and gregarious hatchling. One group included hatchlings before starvation as a control and the other group included those post starvation. Individuals from both groups were weighed on the day of hatching. The hatchlings from the first group were then immediately placed in sealed vials in a freezer $\left(-5^{\circ} \mathrm{C}\right)$. In these analyses, we used only hatchlings from the second group that died after 48 h. i.e., only those insects that actually died of starvation. These were placed in the same freezer after weighed at the day of death. Next, the insects were oven-dried at $60^{\circ} \mathrm{C}$ for 2 days, weighed again and then placed in $1.2 \mathrm{~mL}$ chloroform/methanol (2:1) solution for 3 days, during which the solution was changed twice, according to the method of Watanabe and Tanaka (2000). The total water and lipid contents were calculated by the difference between the fresh body weight and dry weight, and between the dry weight and the lean dry weight, respectively. The percentage of water and lipid contents to body size was calculated by water content/fresh body weight, and lipid content/dry body weight, respectively.

\section{STATISTICAL ANALYSIS}

The egg lengths and number of eggs per pods were compared between egg pods derived from isolated-reared females and from crowd-reared females using $t$-tests. 1-Way ANOVA and Fisher's PLSD post-hoc tests were used to compare the different regions of the egg pods for a given origin. The variances of egg size in a single egg pods were compared between the two groups with F-test. Two-Way ANOVAs were used to analyze the effects of starvation and rearing condition on fresh body weight, dry body weight, water content and lipid content. Significant main effects or interactions were examined using Scheffe's post-hoc tests. Survival rate of solitarious and gregarious hatchling were compared using a Kaplan-Meier test. Differences in the percentages of water and lipid content relative to the body weight at hatching were analyzed using non-parametric Steel-Dwass test ( $\mathrm{R}$ Development Core Team, 2012; software package $\mathrm{R}$, version 2.15.0).

\section{RESULTS}

\section{EFFECT OF REARING DENSITY ON REPRODUCTIVE TRAITS}

The mean egg length per egg pod for isolated-reared group (mean $\pm S E=6.69 \pm 0.06 \mathrm{~mm} ; n=29$ ) was significantly smaller than that for crowd-reared group (mean $\pm S E=7.75 \pm$ $0.06 \mathrm{~mm} ; n=65$ ) (Figure 1A; $t$-test; $t=11.186, d f=1.92 ; P<$ $0.001)$. Egg pods laid by isolated-reared females contained eggs ranging in size from 6.2 to $7.5 \mathrm{~mm}$ in length $(n=29)$. This range partly overlapped with those obtained from the crowdreared group $(6.8-8.7 \mathrm{~mm}, n=65)$. The variance in egg size per egg pod was significantly smaller in the egg pods from isolatedreared females than in those from crowd-reared ones (Figure 1A; $F$-test; $f=2.149, P<0.05)$. A similar tendency was observed when the variances of egg size were compared between the two groups when comparisons of egg size variance were made with values from each group pooled irrespective of egg pod (Figure 1B; $F$-test; $f=2.051, P<0.001)$. However, these significant differences disappeared when considering the coefficient of variation $(\mathrm{CV}=\mathrm{SD} / \mathrm{mean})$ of the egg size $(\mathrm{CV}=0.24$ for isolated-reared, $\mathrm{CV}=0.25$ for crowd-reared, $t$-test, $t=0.726, d f=92, P>$ $0.05)$. Both groups had negatively skewed distribution of egg size (mean skewness $=-0.303$ for isolated-reared and -0.604 for crowd-reared) but were significantly different ( $t$-test; $t=-2.174$, $d f=92, P<0.05)$.

Small differences in egg length were observed along the egg pods produced by isolated-reared females (Figure 2A; ANOVA, $f=5.47, d f=2, P<0.05)$. Fisher's PLSD test revealed that eggs from the upper region were significantly shorter than those

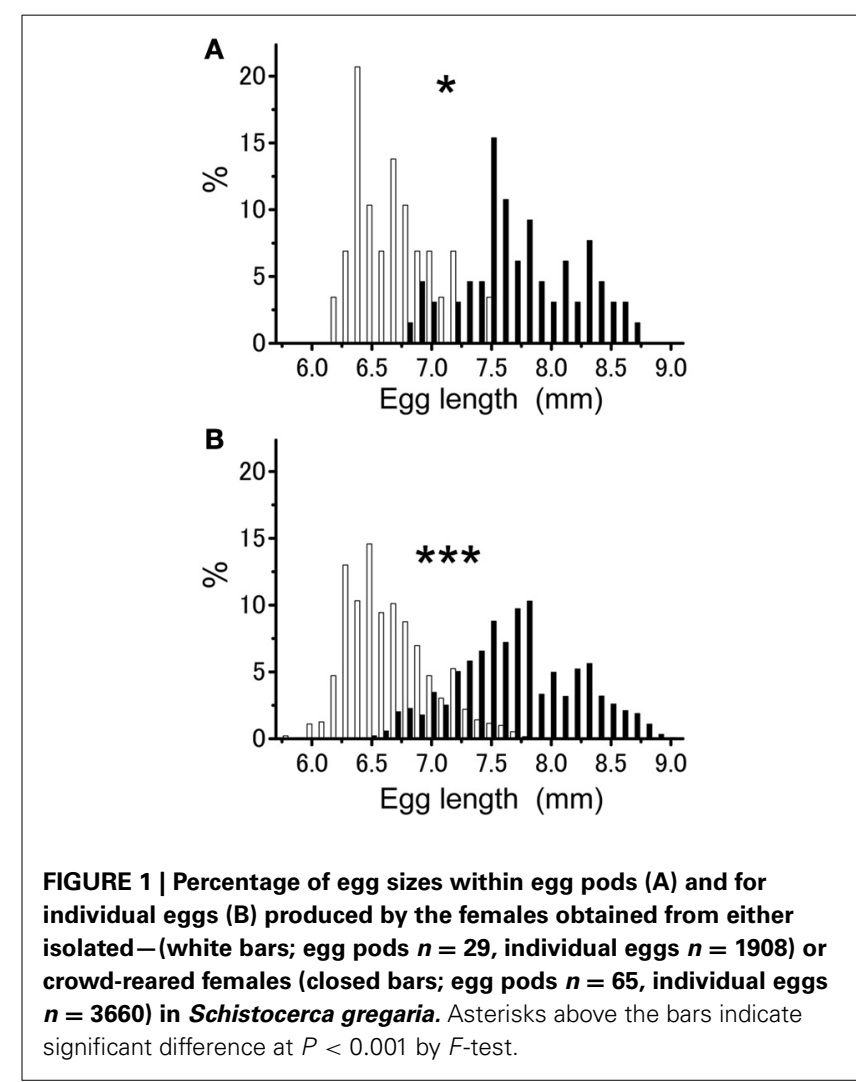




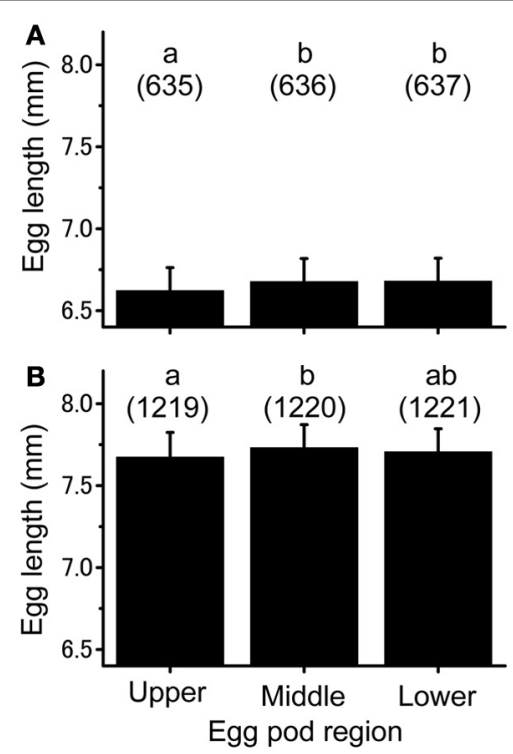

FIGURE 2 | Individual egg size from different regions of the egg pod laid either by the isolation-reared adults $(A)$ or crowd-reared ones (B) of Schistocerca gregaria. Numbers in parentheses indicate sample sizes. Error bars represent standard-deviations. Different letters above each histogram indicate significant differences at $P<0.05$ by Fisher's PLSD post-hoc test.

from the middle $(P<0.05)$ and lower $(P<0.05)$ regions. A similar result was obtained for egg pods produced by crowdreared females, except for the absence of a significant difference between the eggs from the upper and lower parts of the egg pods (ANOVA, $f=3.932, d f=2, P<0.05$; Fisher's PLSD test $P<0.05$, Figure 2B).

The number of eggs per egg pod was also influenced by rearing density. Egg pods produced by isolated-reared females (mean $\pm S E=68.8 \pm 2.9 ; n=29$ ) contained significantly more eggs than those produced by their crowdreared counterparts (mean $\pm S E=58.0 \pm 1.6 ; n=65$ ) ( $t$-test; $t=-3.460, d f=1.92 ; P<0.001)$. Figure 3 illustrates the relationship between the egg size and number of eggs per pod produced by either isolated- or crowd-reared females. The overall correlation involving all eggs produced by the two groups was significantly negative (Pearson's correlation; $r=-0.525 ; z=-5.57 ; n=94 ; P<0.001)$. Similar tendencies were observed for the egg pods produced by isolatedreared females alone (Pearson's correlation; $r=-0.466 ; z=-$ $2.57 ; n=29 ; P<0.01)$ or those produced by crowd-reared ones (Pearson's correlation; $r=-0.444 ; z=-3.75 ; n=65$; $P<0.001)$.

\section{MATERNAL EFFECTS ON STARVATION TOLERANCE OF HATCHLINGS}

The freshly hatched nymphs from isolated-reared females were lighter and greener than the hatchlings from crowdreared females (Table 1). Phase-related differences were observed in the starvation tolerance of the hatchlings (Figure 4). Gregarious hatchlings produced by crowd-reared mothers survived significantly longer than solitarious ones produced by

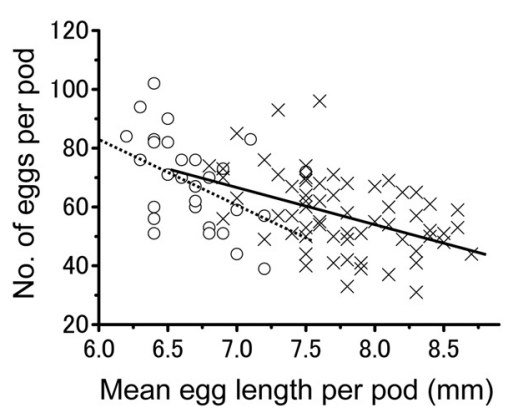

FIGURE 3 | The relationship between egg size and the number of eggs per pod laid by either the isolation-reared adults (open circles) or crowd-reared Schistocerca gregaria (crosses). A negative correlation was found for the isolated group (dotted line, $r=-0.466 ; z=-2.57 ; n=29$; $P<0.01$ ) and crowded group (solid line, $r=-0.444 ; z=-3.75 ; n=65$; $P<0.001$ ).

Table 1 | Characteristics of body weights ( $\mathrm{mg} \pm S D$ ) and body coloration of Schistocerca gregaria hatchlings categorized into five hatchling color grades (HCGs).

\begin{tabular}{llllll}
\hline $\begin{array}{l}\text { Mother's } \\
\text { rearing }\end{array}$ & \multicolumn{5}{c}{ Body weight at hatching (mg) } \\
\cline { 2 - 6 } Density & HCG1 & HCG2 & HCG3 & HCG4 & HCG5 \\
\hline Isolation & $13.6 \pm 1.7$ & $14.8 \pm 0.9$ & $17.3 \pm 2.0$ & $18.3 \pm 1.8$ & 19.1 \\
$N$ & 132 & 11 & 11 & 6 & 1 \\
Crowded & 15.9 & $15.0 \pm 1.7$ & $16.0 \pm 0.7$ & $16.9 \pm 0.5$ & $21.1 \pm 3.0$ \\
$N$ & 1 & 6 & 5 & 4 & 117
\end{tabular}

Hatchlings in HCG 1 are green as typically observed in solitarious phase and those in HCG 5 are almost completely black as observed in gregarious phase. Those in HCGs 2-4 are intermediate in color and increasingly darker (Maeno and Tanaka, 2007).

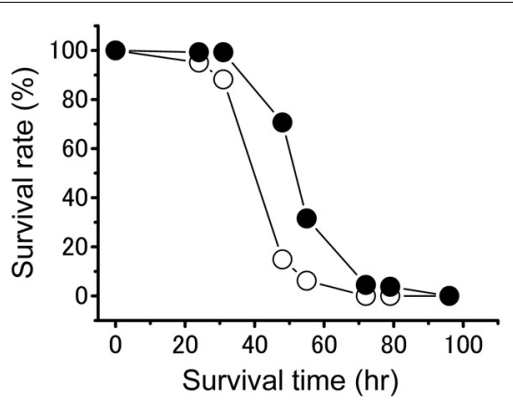

FIGURE 4 | Survival rate of the solitarious hatchlings (open circle, dotted line: from isolated-reared females) and gregarious ones (closed circle, solid line: from crowd-reared ) in Schistocerca gregaria under starvation conditions. Sample size is 161 in the solitarious hatchling group and 133 in the gregarious hatchling group. A Kaplan-Meier test showed a significant difference between the two time series at $P<0.001$.

their isolated-reared counterparts under conditions of starvation (Kaplan-Meier test; $P<0.001$ ).

To investigate the relationship between the survival time and hatchling body weight in more detail, the two values were 


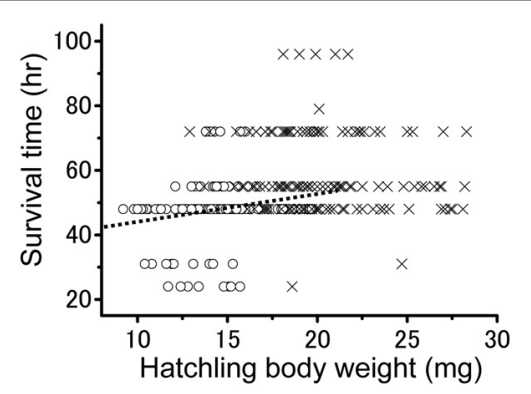

FIGURE 5 | The relationship between hatchling body weight and survival time in solitarious (open circle: from isolated-reared female) and gregarious hatchlings (crosses: from crowd-reared females) in Schistocerca gregaria under starvation conditions. A positive correlation was found only for the solitarious group (dotted line, $r=0.186 ; P<0.01$ ). $n=161$ in the solitarious hatchling group and 133 in the gregarious hatchling group.

individually plotted (Figure 5). The overall correlation involving all the hatchlings produced by the two groups was significantly positive (Pearson's correlation; $r=0.350 ; n=294 ; P<0.001$ ). Survival time was found to significantly increase with body weight at hatching among the solitarious hatchlings (Pearson's correlation; $r=0.186 ; n=161 ; P<0.01$ ), whereas the value was not significant among those in the gregarious line (Pearson's correlation; $r=-0.09 ; n=133 ; P>0.05)$. In fact, relatively small gregarious hatchlings survived just as long as the large ones.

\section{MATERNAL EFFECTS ON THE PHYSIOLOGICAL TRAITS OF HATCHLINGS ASSOCIATED WITH STARVATION}

No significant difference was found in the fresh body weight of the hatchlings, between the hatchlings used for starvation experiments and control for both solitarious and gregarious hatchling groups $(f=0.01, d f=1, P>0.05$, Table 2; Figure 6A). Fresh body weight was significantly greater in gregarious hatchlings than in the solitarious ones $(f=507.65, d f=1, P<$ 0.001, Table 2; Figure 6A). A similar phase-related difference was observed for dry body weight $(f=461.0, d f=1, P<0.001$, Table 2; Figure 6B), water content $(f=471.98, d f=1, P<$ 0.001, Table 2; Figure 6C), as well as lipid content $(f=87.43$, $d f=1, P<0.001$, Table 2; Figure 6D), and the three variables significantly decreased after starvation in both the solitarious and gregarious groups (dry body weight, $f=74.20, d f=1, P<$ 0.001 ; water content $f=222.25, d f=1, P<0.001$; lipid content, $f=179.57, d f=1, P<0.001$, Table 2; Figure 6). These three variables were positively correlated to hatchling body weight in both solitarious and gregarious hatchlings, except for the lipid contents of hatchlings after starvation (Table 3; Figure 7). The percentage of water content relative to the fresh body weight at hatching significantly decreased post starvation in both solitarious and gregarious hatchling groups (Figure 8A; Steel-Dwass test; $P<0.05$ ); however, the values from the two hatchling groups were almost identical before and after starvation (Steel-Dwass test; $P>0.05)$. Starvation also caused a drop in the percentage of lipid content relative to the dry body weight in both hatchling groups, although the values before starvation were
Table 2 | Two way analysis of variance for fresh body weight (mg), water contents $(\mathrm{mg})$, dry body weight $(\mathrm{mg})$ and lipid contents $(\mathrm{mg})$ for Schistocerca gregaria hatchlings from either isolated-reared (solitarious) or crowd-reared (gregarious) females.

\begin{tabular}{|c|c|c|c|c|}
\hline Source of variance & $d f$ & MS & $f$ & $\boldsymbol{P}$ \\
\hline \multicolumn{5}{|c|}{ FRESH BODY WEIGHT } \\
\hline Phase & 1 & 2427.61 & 507.65 & $<0.001$ \\
\hline Starvation & 1 & 23.90 & 5.00 & $<0.05$ \\
\hline Phase $\times$ starvation & 1 & 0.06 & 0.01 & $>0.05$ \\
\hline Error & 217 & 4.78 & & \\
\hline \multicolumn{5}{|l|}{ DRY BODY WEIGHT } \\
\hline Phase & 1 & 62.92 & 461.00 & $<0.001$ \\
\hline Starvation & 1 & 10.13 & 74.20 & $<0.001$ \\
\hline Phase $\times$ starvation & 1 & 0.04 & 0.30 & $>0.05$ \\
\hline Error & 217 & 0.14 & & \\
\hline \multicolumn{5}{|l|}{ WATER CONTENT } \\
\hline Phase & 1 & 1404.70 & 471.98 & $<0.001$ \\
\hline Starvation & 1 & 661.47 & 222.25 & $<0.001$ \\
\hline Phase $\times$ starvation & 1 & 15.27 & 5.13 & $<0.05$ \\
\hline Error & 217 & 3.00 & & \\
\hline \multicolumn{5}{|l|}{ LIPID CONTENT } \\
\hline Phase & 1 & 3.53 & 87.43 & $<0.001$ \\
\hline Starvation & 1 & 7.25 & 179.57 & $<0.001$ \\
\hline Phase $\times$ starvation & 1 & 0.98 & 24.20 & $<0.001$ \\
\hline Error & 217 & 0.04 & & \\
\hline
\end{tabular}

significantly higher in the gregarious hatchlings than in the solitarious ones (Figure 8B). The difference, however, ceased to be significant between the two groups post starvation (Figure 8B; Steel-Dwass test; $P>0.05)$. For solitarious hatchlings, the percentage of water content relative to the fresh body weight at hatching positively correlated with hatchling body weight before starvation, while this tendency became negative after starvation (Figure 9A; Table 4). On the other hand, it was relatively constant for gregarious hatchlings (Figure 9A; Table 4). Hatchling bodyweight was correlated to relative lipid content only for gregarious hatchlings pre-starvation (Figure 9B; Table 4).

\section{DISCUSSION}

\section{DENSITY-DEPENDENT REPRODUCTIVE CHARACTERISTICS}

Crowding experienced by the mother as an adult influences both the size and number of progeny in S. gregaria. As reported previously (Norris, 1952; Hunter-Jones, 1958; Uvarov, 1966; Injeyan and Tobe, 1981; Maeno and Tanaka, 2008a), the present study confirmed that our Mauritanian strain of desert locust also exhibit modified egg size and number in response to rearing density. The isolated-reared females produced smaller but more eggs than did the crowd-reared females. We also observed that the variance in egg size in the egg pods was greater when produced by crowd-reared females than when deposited by their isolatedreared counterparts. However, the coefficients of variation were similar for both treatments. These results suggest that variability in egg size between solitarious and gregarious phases is not linked to a phase-specific strategy. We also observed that the skewness of egg size was negative for both phase. These long tails on the 
left side of the egg-size distributions suggest that there is generally a spread of eggs smaller than the targeted size. This could be interpreted as a common phenomenon that makes a difference between the actual mean egg sizes that the females arrive to get and the optimum that they try to get (the mode of the distribution) depending on their history. The significant difference observed for this skewness is linked to the facts that (1) gregarious females tend to have larger eggs than solitarious ones (making the optimum further away than the actual possible size) but (2) small failed eggs exist for both (spreading the distribution more for the gregarious group). These observations argue for physiological processes that selectively allow gregarious females to produce bigger eggs but do not argue for an additional risk-spreading strategy
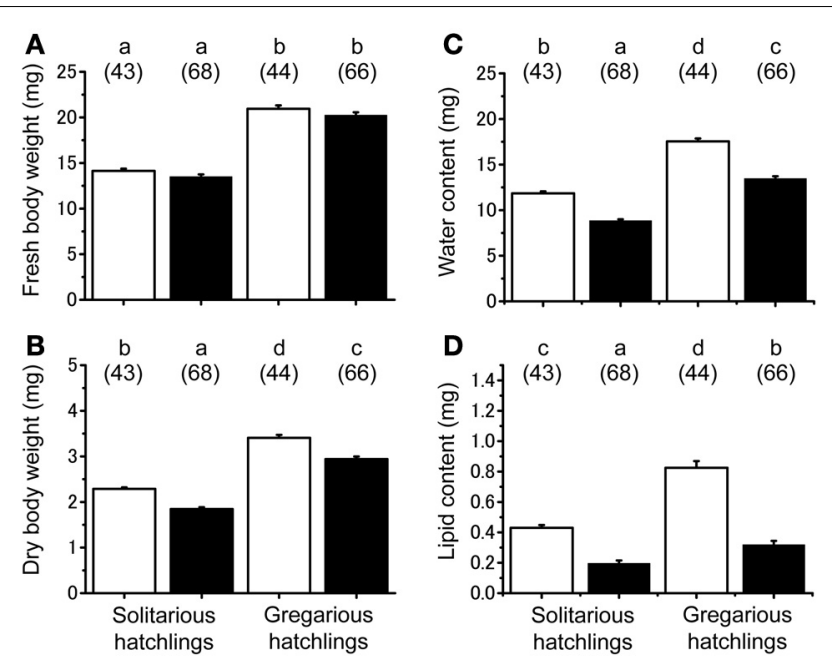

FIGURE 6 | Physiological changes associated with starvation in hatchlings produced by solitarious hatchings (from isolated-reared mothers) and gregarious ones (from crowd-reared females) in Schistocerca gregaria. (A) Fresh body weight; (B) dry body weight; (C) water content; (D) lipid content. Each variable was measured before (open bar) and after starvation (closed bar). Numbers in parentheses indicate sample sizes. Different letters above each bar indicate significant differences at $P<0.05$ by Scheffé's post-hoc test. Vertical lines indicate SE. (i.e., bet-hedging; Hopper, 1999) that gregarious females would use by varying their eggs' sizes.

Mixtures of characteristics of solitarious and gregarious hatchlings appearing from single egg pods were previously documented (Faure, 1932; Husain and Ahmad, 1936; Hunter-Jones, 1958; Bouaïchi et al., 1995; McCaffery et al., 1998; Tanaka and Maeno, 2006). Different hatchlings may come from different egg sizes within the egg pods, because the degree of darkness of the body is correlated with egg size (Tanaka and Maeno, 2008). The present study supports this idea and provides another physiological factor that may contribute to the effect: the distribution of sizes within the egg pod. However, this assumes that all ovarioles do not produce eggs of the same size simultaneously.

The present study observed that the variation in egg size was larger in the egg pods produced by crowd-reared females than

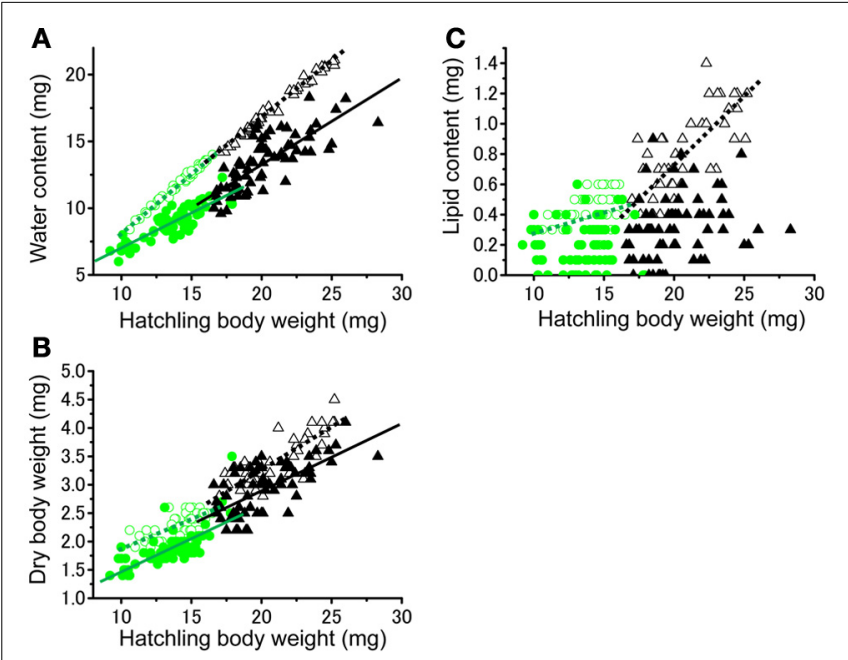

FIGURE 7 | Relationship between hatchling body weight at hatching and water contents (A), dry body weight (B), and lipid contents (C) of either solitarious $(O, \bullet)$ or gregarious hatchlings $(\Delta, \Delta)$ of Schistocerca gregaria pre- $(O, \Delta)$ or post- $(\bullet, \Delta)$ starvation. Regression lines are drawn when significant (green for the solitarious, black for gregarious, dotted line for pre-starvation, solid line for post-starvation). See Table 3 for statistical results.

Table 3 | Matrices of statistical correlation (Pearson correlation, $r$, $z$-value) between fresh body weight (mg) and water contents (mg), dry body weight $(\mathrm{mg}$ ) or lipid contents $(\mathrm{mg})$ for Schistocerca gregaria hatchlings from either isolated-reared (solitarious) or crowd-reared (gregarious) females.

\begin{tabular}{|c|c|c|c|c|c|}
\hline Phase & Treatment & Water contents (mg) & Dry body weight (mg) & Lipid contents (mg) & $n$ \\
\hline Solitarious & $\begin{array}{l}\text { Pre-starvation } \\
\text { (control) }\end{array}$ & $\begin{array}{l}r=0.994, z=18.10 \\
* * *\end{array}$ & $\begin{array}{l}r=0.693, z=5.40 \\
* * *\end{array}$ & $\begin{array}{l}r=0.375, z=2.49 \\
*\end{array}$ & 43 \\
\hline Gregarious & $\begin{array}{l}\text { Pre-starvation } \\
\text { (control) }\end{array}$ & $\begin{array}{l}r=0.993, z=18.04 \\
* * *\end{array}$ & $\begin{array}{l}r=0.818, z=7.36 \\
* * *\end{array}$ & $\begin{array}{l}r=0.742, z=6.11 \\
* * *\end{array}$ & 44 \\
\hline Solitarious & Post-starvation & $\begin{array}{l}r=0.867, z=10.65 \\
* * *\end{array}$ & $\begin{array}{l}r=0.707, z=7.10 \\
* * *\end{array}$ & $\begin{array}{l}r=0.041, z=0.33 \\
\text { NS }\end{array}$ & 68 \\
\hline Gregarious & Post-starvation & $\begin{array}{l}r=0.770, z=8.11 \\
* * *\end{array}$ & $\begin{array}{l}r=0.668, z=6.40 \\
* * *\end{array}$ & $\begin{array}{l}r=0.235, z=1.90 \\
\text { NS }\end{array}$ & 66 \\
\hline
\end{tabular}

Hatchlings were exposed to either starvation or not as a control. Pearson correlation: NS, not significant, ${ }^{*} P<0.05 ;{ }^{* * *} P<0.001$. 

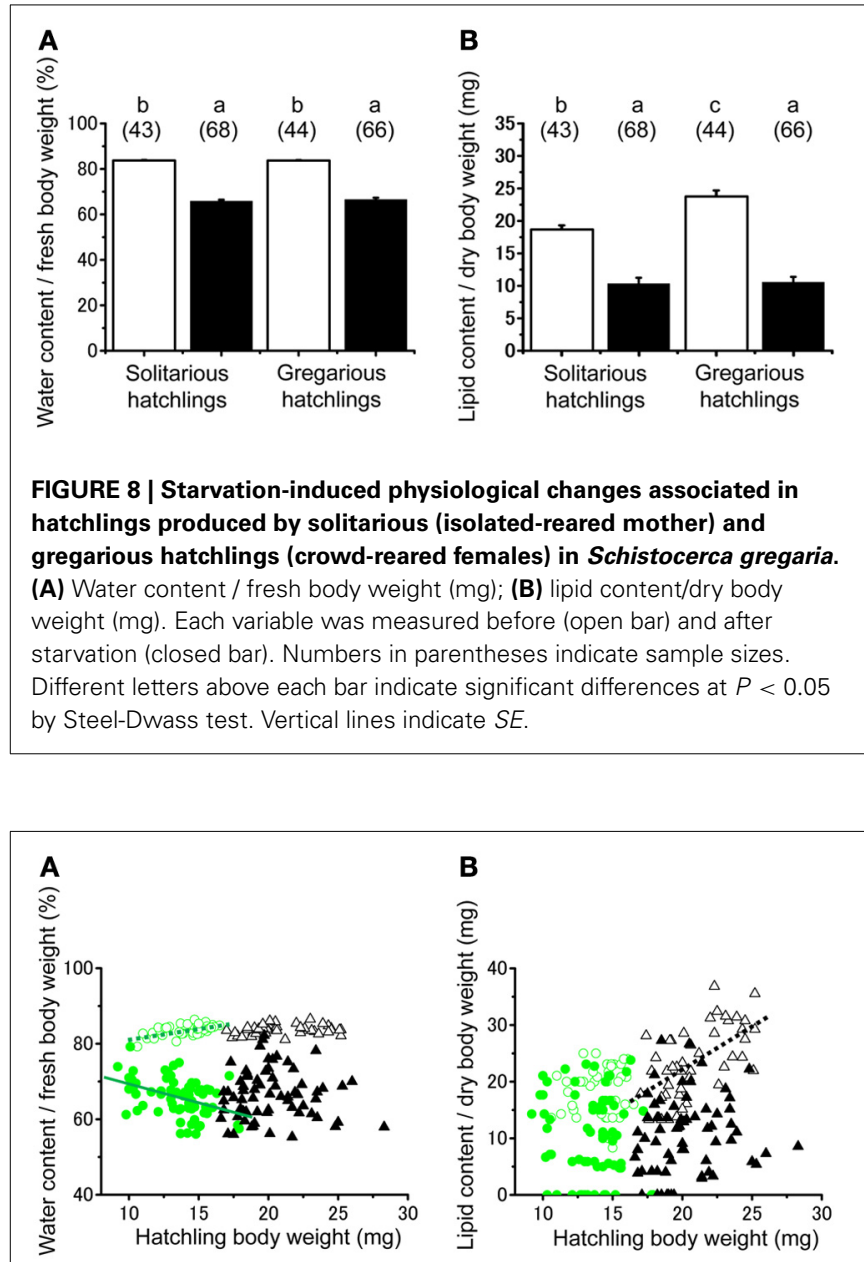

FIGURE 9 | Relationships between hatchling body weight at hatching and the ratios of percentage of water content / fresh body weight (A) or percentage of lipid content / dry body weight (B) of either solitarious $(O, \bullet)$ or gregarious hatchlings $(\Delta, \Delta)$ of Schistocerca gregaria pre- $(O, \Delta)$ or post- $(\bullet, \Delta)$ starvation. Regression lines are drawn when significant (green for the solitarious, black for gregarious, dotted line for pre-starvation, solid line for post-starvation). See Table $\mathbf{4}$ for statistical results.

those by isolated ones. Phase-related reproductive traits could explain the different degrees of variation in egg size between the two groups. In S. gregaria, the longer the duration of the interval between ovipositions the bigger the mean egg size per egg pod (Maeno and Tanaka, 2009b). Crowded conditions tend to increase the interval between ovipositions and therefore also increase egg size (Maeno and Tanaka, 2009b). Although the present study did not record the ovipositional interval individually under crowded conditions, there is a possibility that such a long ovipositional interval could be a factor that also influences the large variation in egg size within a single egg pod. Different oocyte sizes were observed among the ovarioles during oocyte development, for both the solitarious and gregarious females (Maeno, unpublished observations). Differences in egg development among the ovarioles also appear to cause a variation in egg size. Further study is necessary to better understand the physiological mechanisms controlling progeny quality and quantity.

In S. gregaria, a trade-off between progeny size and number was observed for the solitarious locusts, although not for the gregarious ones (Maeno and Tanaka, 2008a). In contrast, the present study found a trade-off even for egg pods produced by gregarious (crowd-reared) females. The discrepancy between the two studies can be explained by variations in the reproductive cycle. The first egg pods produced by the gregarious locusts contained substantial numbers of small eggs which in turn produced green hatchlings typical of the solitarious (isolated-reared) phase, whereas those deposited after the first egg pod predominantly produced black hatchlings, typical of the gregarious phase (Maeno and Tanaka, 2008 b). Although the present study did not record the reproductive cycle, all the egg pods collected were used for the analysis. The earlier study did not use the first egg pods produced by the crowd-reared females for analysis (Maeno and Tanaka, 2008a), which may explain why they did not observe the trade-off. The process by which egg size and egg number per clutch are controlled in the ovary remains unclear. Desert locusts allometrically modify their egg size and number in response to a change in rearing density (Maeno and Tanaka, 2008a). The number of eggs decreased with increased egg size when isolated-reared females were exposed to crowding (Maeno and Tanaka, 2008a). Juvenile hormone was long believed to cause reproductive solitarization (i.e., producing smaller and more eggs) (Pener, 1991), but more recent work suggests it may not be involved (Maeno and Tanaka, 2009b; Verlinden et al., 2009).

\section{PHASE-RELATED PROGENY FITNESS AND PHYSIOLOGICAL TRAITS OF HATCHLINGS ASSOCIATED WITH STARVATION}

Progeny body size influences fitness-related performance in insects (Fox and Czesak, 2000). Large gregarious hatchlings showed better survival rate and developmental performance than small solitarious ones (Maeno and Tanaka, 2008b, 2011). The present study confirmed the observation by Albrecht and Blackith (1960) that under starvation conditions gregarious hatchlings with large body size survived longer than solitarious ones with small body size. Additionally, the present study further demonstrated that the gregarious hatchlings showed specific body sizedependent survival patterns. Among the solitarious hatchlings, the survival time increased proportionally to the increase in body weight as generally observed, whereas the relatively small gregarious hatchlings survived as long as the large ones. In fact, even though the range of body sizes was greater in gregarious hatchlings, the survival time was almost constant, suggesting that gregarization in hatchlings might be related to fitness-related survivorship.

The initial energy supply of hatchlings was determined by the mothers. Thus far, lipids have been considered the main resource of energy not only for embryonic development but also for hatchlings (Arrese and Soulages, 2010). Our lipid content measures and the difference among solitarious and gregarious hatchlings were in agreement with Blackith and Howden (1961) except for the range of values, which probably is due to different techniques.

The present study demonstrated that the energy reserve and utilization patterns differed between solitarious and gregarious 


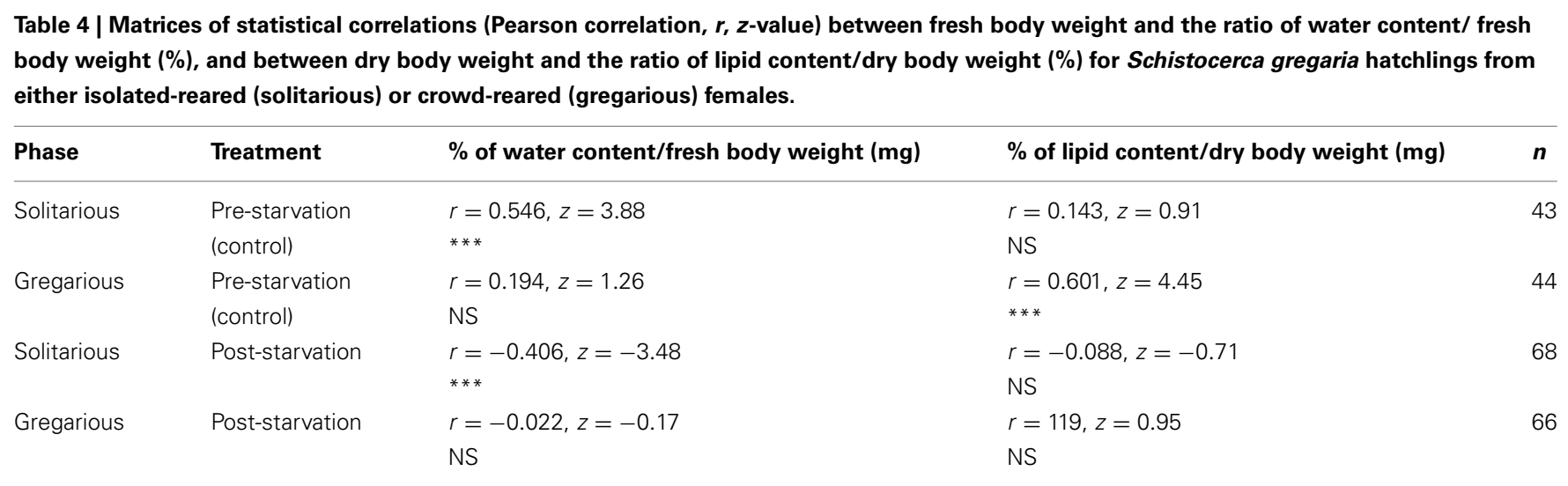

Hatchlings were exposed to either starvation or not as a control. Pearson correlation: NS, not significant, ${ }^{* * *} P<0.001$.

hatchlings. The initial percentage of lipid relative to body weight was greater in the gregarious hatchlings than in the solitarious ones. Among gregarious hatchlings, this proportion increased as body size increased; however, after starvation it became equal to that of solitarious hatchlings. The initial high percentage of lipid content relative to the body size in the gregarious hatchlings could play an important physiological role to enhance survival under certain conditions. Hatchlings began to walk actively in the experimental cylinder when they were hungry (data not shown). Gregarious hatchlings are well known to be more active than solitarious ones (Ellis and Pearce, 1962; Uvarov, 1966; Bouaïchi et al., 1995; Simpson et al., 1999; Hoste et al., 2006; Harano et al., 2012), and it has been presumed that hatchlings' activity and metabolism rate are positively correlated to body size. Although the present study did not measure the total activity of hatchlings, there is a possibility that the survival time of the large gregarious hatchlings was limited by their faster metabolism of energy reserves compared to that by small gregarious hatchlings. However, Blackith and Howden (1961) suggested that non-fatty substances also may act as energy sources.

In S. gregaria, water is absorbed by the egg itself during embryonic development (Shulov and Pener, 1963). Blackith (1961) reported that the longer survival of the large unfed hatchlings is attributable to their greater initial water reserves. The present study confirmed that water was consumed during starvation, although the percentage of water weight relative to fresh body weight was almost identical between the solitarious and gregarious hatchlings. The utilization pattern of water was body-size dependent for solitarious hatchlings, but not for gregarious ones: larger solitarious hatchlings had higher percentage of water relative to body weight, whereas no significant correlation was found among gregarious hatchlings. These different physiological changes might not be explained by only body size, but phase-specific characteristics.

\section{CONCLUSION}

In conclusion, the maternal response to crowding, by increasing progeny size and the degree of variation in progeny size via trade-offs between progeny quality and quantity, appeared to be an advantageous method to cope with the adverse environments as observed during outbreak. In S. gregaria, gregarious adult females aggregate together and lay eggs in groups (Stower et al., 1958). Hatchlings from these eggs would sometimes suffer from unpredictable severe competition for food resources because the vegetation would have already been damaged by their parents. Also, conspecific individuals would synchronously hatch within the limited area, and might have little choice of food plants. Under such conditions, it would be beneficial for the female to produce large gregarized hatchlings that carry relatively large amounts of lipid as energy reserve conferring them high survivorship irrespective of their size. Consistent with this idea, a high percentage of gregarious progeny demonstrate greater tolerance for starvation and greater locomotion, thus increasing the likelihood of survival until they can reach an alternate food source. On the other hand, the solitarious hatchlings are likely to find themselves in areas where vegetation is available (Uvarov, 1977). Increasing the reproductive resource allocation to the number of progeny instead of to size as observed for the isolated-reared females appears to be a favorable strategy when the survival between the small and large hatchlings is almost similar. Such reproductive and survival strategies adopted by the desert locusts could play an important role in contributing to the population growth. Kaplan and Cooper (1984) predicted that with variable environments, traits allowing variable offspring size are selected. Desert locusts are widely distributed and migrate over long distances, dealing with various types of environments (Uvarov, 1977), which could have favored the evolution of variability in the phase-related strategies.

\section{ACKNOWLEDGMENTS}

We sincerely thank Benjamin Pélissié, Christine Pagés, JeanMichel Vassal, Marie-Pierre Chapuis, Hélène Jourdan, Antoine Foucart, Laurence Schmitt, Pierre-Emmanuel Gay, Mohamed El Hacen Jaavar, Sid'Ahmed Ould Mohamed, Sidi Ould Ely and other personnel of CNLA in Mauritania for their encouragement, support and stimulating discussions. This study was funded by the Japan Society for the Promotion for Science through a research abroad fellowship for Koutaro O. Maeno (No. 128.2011), by a Narishige Zoological Science Award to Koutaro O. Maeno funded in part by the Ministry of Agriculture, Forestry, and Fisheries (MAFF) of Japan through the Japan-CGIAR Fellowship Program implemented by Japan International Research Center 
for Agricultural Sciences (JIRCAS), and supported by Grants-inAid for Scientific Research (KAKENHI) Grant Number 24405027, from the Japan Society for the Promotion of Science (JSPS). Two anonymous referee significantly improved the manuscript.

\section{REFERENCES}

Albrecht, O. F., and Blackith, R. E. (1960). Poids et délai de survie des larves nouveau-nées chez les acridiens migrateurs. Données physiologiques. C. $R$. Acad. Sci. Paris 250, 3388-3390.

Arrese, E. L., and Soulages, J. L. (2010). Insect fat body: energy, metabolism, and regulation. Annu. Rev. Entomol. 55, 207-225. doi: 10.1146/annurev-ento112408-085356

Babah, E. M. A. (2010). Biogéographie du Criquet pèlerin en Mauritanie. Paris: Hermann.

Blackith, R. E. (1961). The water reserves of hatchling locusts. Comp. Biochem. Physiol. 3, 99-107. doi: 10.1016/0010-406X(61) 90136-0

Blackith, R. E., and Howden, G. F. (1961). The food reserves of hatchling locusts. Comp. Biochem. Physiol. 3, 108-124. doi: 10.1016/0010-406X(61) 90137-2

Bouaïchi, A., Roessingh, P., and Simpson, S. J. (1995). Analysis of the behavioural effects of crowding and re-isolation on solitary-reared adult desert locusts (Schistocerca gregaria) and their offspring. Physiol. Entomol. 20, 199-208. doi: 10.1111/j.1365-3032.1995.tb00002.x

Capinera, J. L. (1979). Qualitative variation in plants and insects: effect of propagule size on ecological plasticity. Am. Nat. 114, 350-361. doi: 10.1086/ 283484

Ellis, P. E., and Pearce, A. (1962). Innate and learned behaviour patterns that lead to group formation in locust hoppers. Anim. Behav. 10, 305-318. doi: 10.1016/0003-3472(62)90054-4

Faure, J. C. (1932). The phases of locusts in South Africa. Bull. Entomol. Res. 23, 293-405. doi: 10.1017/S0007485300004223

Fox, C. W., and Czesak, M. E. (2000). Evolutionary ecology of progeny size in arthropods. Annu. Rev. Entomol. 45, 341-369. doi: 10.1146/annurev.ento.45.1.341

Hägele, B. F., Oag, V., Bouaïchi, A., McCaffery, A. R., and Simpson, S. J. (2000). The role of female accessory glands in maternal inheritance of phase in the desert locust Schistocerca gregaria. J. Insect Physiol. 46, 275-280. doi: 10.1016/S00221910(99)00180-8

Harano, K., Tanaka, S., Watari, Y., and Saito, O. (2012). Phase-dependent locomotor activity in ?rst-stadium nymphs of the desert locust, Schistocerca gregaria: effects of parental and progeny rearing density. J. Insect Physiol. 58, 718-725. doi: 10.1016/j.jinsphys.2012.02.007

Hopper, K. R. (1999). Risk-spreading and bet-hedging in insect population biology. Annu. Rev. Entmol. 44, 535-560. doi: 10.1146/annurev.ento. 44.1.535

Hoste, B., Sas, F., Vandersmissen, T., De Loof, A., Breuer, M., and Huybrechts, J. (2006). A miniaturized assay to quantify effects of chemicals or physical stimuli upon locust activity. Insect Sci. 13, 401-407. doi: 10.1111/j.17447917.2006.00109.x

Hunter-Jones, P. (1958). Laboratory studies on the inheritance of phase characters in locusts. Anti-Locust Bull. 29, 1-32.

Husain, M. A., and Ahmad, T. (1936). Studies on Schistocerca gregaria Forsk. VI. Influence of temperature on the intensity and extent of black pattern in the desert locust hoppers bred crowded. Indian J. Agricul. Sci. 6, 624-664.

Injeyan, H. S., and Tobe, S. S. (1981). Phase polymorphism in Schistocerca gregaria: reproductive parameters. J. Insect Physiol. 27, 97-102. doi: 10.1016/00221910(81)90115-3

Islam, M. S., Roessingh, P., Simpson, S. J., and McCaffery, A. R. (1994). Effects of population density experienced by parents during mating and oviposition on the phase of hatchling desert locusts, Schistocerca gregaria. Proc. R. Soc. B 257, 93-98. doi: 10.1098/rspb.1994.0099

Kaplan, R. H., and Cooper, W. S. (1984). The evolution of developmental plasticity in reproductive characteristics: an application of the "adaptive coin-flipping" principle. Am. Nat. 123, 393-410. doi: 10.1086/ 284211
Maeno, K., and Tanaka, S. (2007). Effects of hatchling body colour and rearing density on body colouration in last stadium nymphs of the desert locust, Schistocerca gregaria (Forskål) (Orthoptera: Acrididae). Physiol. Entomol. 32, 87-94. doi: 10.1111/j.1365-3032.2006. 00546.x

Maeno, K., and Tanaka, S. (2008a). Maternal effects on progeny size, number and body color in the desert locust, Schistocerca gregaria: density- and reproductive cycle-dependent variation. J. Insect Physiol. 54, 1072-1080. doi: 10.1016/j.jinsphys.2008.04.010

Maeno, K., and Tanaka, S. (2008b). Phase-specific developmental and reproductive strategies in the desert locust. Bull. Entomol. Res. 98, 527-534. doi: 10.1017/S0007485308006044

Maeno, K., and Tanaka, S. (2009a). The trans-generational phase accumulation in the desert locust, Schistocerca gregaria: morphometric changes and extra molting. J. Insect Physiol. 55, 1013-1020. doi: 10.1016/j.jinsphys.2009. 07.005

Maeno, K., and Tanaka, S. (2009b). Is juvenile hormone involved in the maternal regulation of egg size and progeny characteristics in the desert locust? J. Insect Physiol. 55, 1021-1028. doi: 10.1016/j.jinsphys. 2009.08.014

Maeno, K., and Tanaka, S. (2010). Epigenetic transmission of phase in the desert locust, Schistocerca gregaria: determining the stage sensitive to crowding for the maternal determination of progeny characteristics. J. Insect Physiol. 56, 1883-1888. doi: 10.1016/j.jinsphys.2010.08.010

Maeno, K., and Tanaka, S. (2011). Phase-specific responses to different food qualities in the desert locust, Schistocerca gregaria; developmental, morphological and reproductive characteristics. J. Insect Physiol. 57, 514-520. doi: 10.1016/j.jinsphys.2011.02.004

Maeno, K., and Tanaka, S. (2012). Adult female desert locust require contact chemicals and light for progeny gregarization. Physiol. Entomol. 37, 109-118. doi: 10.1111/j.1365-3032.2011.00812.x

Maeno, K., Tanaka, S., and Harano, K. (2011). Tactile stimuli perceived by the antennae cause the isolated females to produce gregarious offspring in the desert locust, Schistocerca gregaria. J. Insect Physiol. 57, 74-82. doi: 10.1016/j.jinsphys.2010.09.009

McCaffery, A. R., Simpson, S. J., Islam, M. S., and Roessingh, P. (1998). A gregarizing factor present in the egg pod foam of the desert locust Schistocerca gregaria. J. Exp. Biol. 201, 347-363.

Norris, J. M. (1952). Reproduction in the desert locust (Schistocerca gregaria Forskal) in relation to density and phase. Anti-Locust Bull. 13, 1-51.

Pener, M. P. (1991). Locust phase polymorphism and its endocrine relations. Adv. Insect Physiol. 23, 1-79. doi: 10.1016/S0065-2806(08) 60091-0

Pener, M. P., and Simpson, S. J. (2009). Locust phase polyphenism: an update. Adv. Insect Physiol. 36, 1-272. doi: 10.1016/S0065-2806(08) 36001-9

Pener, M. P., and Yerushalmi, Y. (1998). The physiology of locust phase polymorphism: an update. J. Insect Physiol. 44, 365-377. doi: 10.1016/S00221910(97)00169-8

R Development Core Team. (2012). R: A language and environment for statistical computing. Vienna: R Foundation for Statistical Computing. Available online at: http://www.R-project.org

Shulov, A., and Pener, M. P. (1963). Studies on the development of eggs of the desert locust (Schistocerca gregaria Forskål) and its interruption under particular conditions of humidity. Anti-Locust Bull. 41, $1-59$.

Simpson, S. J., McCaffery, A. R., and Hägele, B. F. (1999). A behavioural analysis of phase change in the desert locust. Biol. Rev. Camb. Philos. Soc. 74, 461-480. doi: 10.1017/S000632319900540X

Stower, W. J., Popov, G. B., and Greathead, D. J. (1958). Oviposition behaviour and egg mortality of desert locust on the coast of Eritrea. Anti-Locust Bull. 30, 1-33.

Tanaka, S., and Maeno, K. (2006). Phase-related body-color polyphenism in hatchlings of the desert locust, Schistocerca gregaria: re-examination of the maternal and crowding effects. J. Insect Physiol. 52, 1054-1061. doi: 10.1016/j.jinsphys.2006.07.004

Tanaka, S., and Maeno, K. (2008). Maternal effects on progeny body size and color in the desert locust, Schistocerca gregaria: examination of a current view. J. Insect Physiol. 54, 612-618. doi: 10.1016/j.jinsphys.2007. 12.010 
Uvarov, B. (1966). Grasshoppers and Locusts, Vol. 1. Cambridge: Cambridge University Press.

Uvarov, B. (1977). Grasshoppers and Locusts, Vol. 2. London: Centre for Overseas Pest Research.

Van Wielendaele, P., Dillen, S., Marchal, E., Badisco, L., and Vanden Broeck, J. (2012). CRF-like diuretic hormone negatively affects both feeding and reproduction in the desert locust, Schistocerca gregaria. PLoS ONE 7:e31425. doi:10.1371/journal.pone. 0031425

Verlinden, H., Badisco, L., Marchal, E., Van Wielendaele, P., and Vanden Broeck, J. (2009). Endocrinology of reproduction and phase transition in locusts. Gen. Comp. Endocrinol. 15, 79-92. doi: 10.1016/j.ygcen.2008. 11.016

Watanabe, M., and Tanaka, K. (2000). Hormonal control of diapause and overwintering traits in a leaf beetle, Aulacophora nigripennis. Physiol. Entomol. 25, 337-345. doi: 10.1046/j.1365-3032.2000. 00202.x
Conflict of Interest Statement: The authors declare that the research was conducted in the absence of any commercial or financial relationships that could be construed as a potential conflict of interest.

Received: 19 August 2013; accepted: 08 November 2013; published online: 04 December 2013.

Citation: Maeno KO, Piou C, Ould Babah, MA and Nakamura S (2013) Eggs and hatchlings variations in desert locusts: phase related characteristics and starvation tolerance. Front. Physiol. 4:345. doi: 10.3389/fphys.2013.00345

This article was submitted to Integrative Physiology, a section of the journal Frontiers in Physiology.

Copyright (C) 2013 Maeno, Piou, Ould Babah and Nakamura. This is an openaccess article distributed under the terms of the Creative Commons Attribution License (CC BY). The use, distribution or reproduction in other forums is permitted, provided the original author(s) or licensor are credited and that the original publication in this journal is cited, in accordance with accepted academic practice. No use, distribution or reproduction is permitted which does not comply with these terms. 